\title{
Berkshire Encyclopedia of World Sport
}

Levinson, David; Pfister, Gertrud Ursula

Publication date:

2013

Document version

Early version, also known as pre-print

Citation for published version (APA):

Levinson, D., \& Pfister, G. U. (Eds.) (2013). Berkshire Encyclopedia of World Sport. (3 ed.) Berkshire Publishing Group. 


\section{BERKSHIRE Encyclopedia of World Sport, Third Edition}
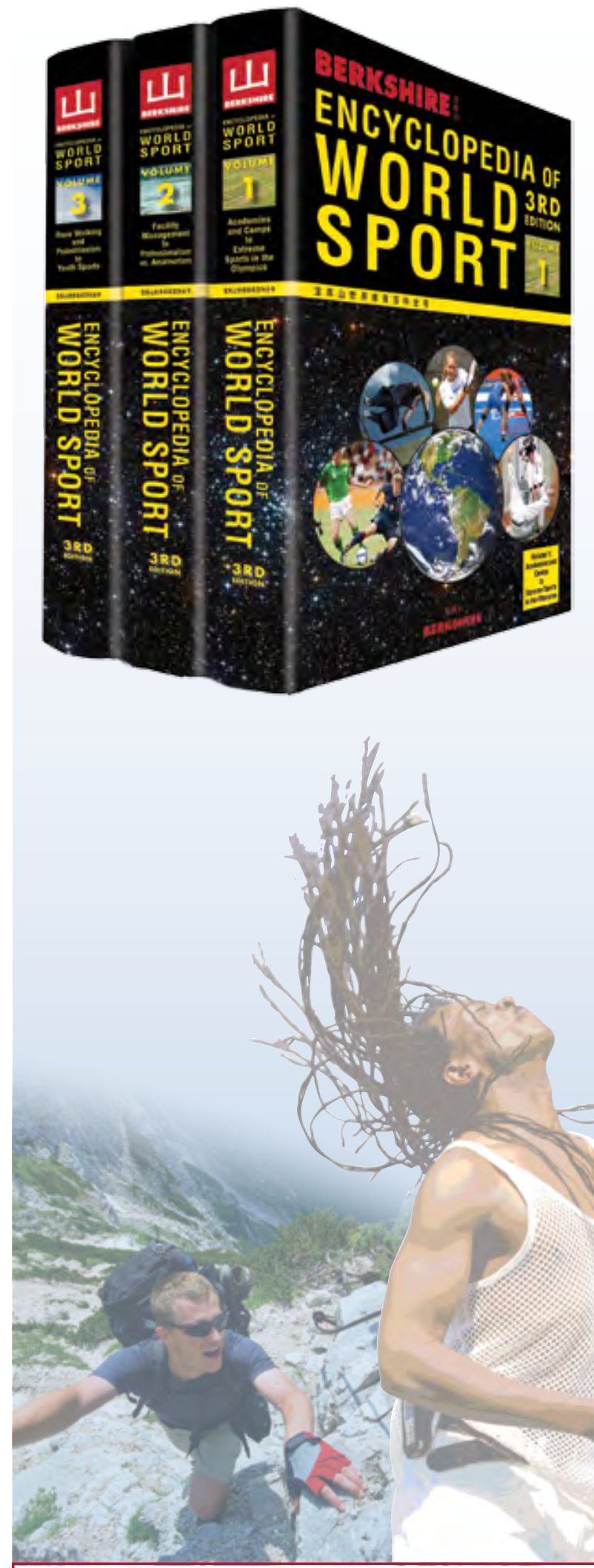

For more information: Berkshire Publishing Group cservice@berkshirepublishing.com • www.berkshirepublishing.com 122 Castle Street • Great Barrington, MA 01230-1506 • USA

\author{
1,800 pages, 3 hardcover, library-bound volumes, US\$499 \\ ISBN: 978-19933782-67-6. eISBN: 978-1-933782-62-1. \\ Third edition, 2013 \\ Editors: David Levinson and Gertrud Pfister
}

The renowned Berkshire Encyclopedia of World Sport covers the culture, history, and business of sports around the world. The third edition of this groundbreaking work brings the study of sports into the 21st century by integrating Berkshire's past work on women's sports and extreme sports into a complete sporting library: a perfect addition for any library.

The new three-volume set includes over $\mathbf{3 0 0}$ updated and new articles on:

- sports management and marketing

- every sport from buzkashi to motorcycle polo

- sports medicine

- the Olympics, past and future

- environmental and economic issues

The third edition includes::

- short, easily digestible article abstracts and keywords

- tables of upcoming Olympics events

- sports-related quotes

- foreword by London Organising Committee Chairman and Olympic

The Times (London) called the first edition of the Encyclopedia of World Sport "the newest sporting bible." Berkshire sports titles have been praised by $G Q$ magazine, $L a$ Gazzetta dello Sport, and the UK bookmakers William Hill, and received awards from Choice, Library Journal, and Booklist.

- Click these links for lists of articles, contributors, and upcoming Olympic events.

bit.ly/world-sport-articles $\bullet$ bit.ly/world-sport-3-contributors $\bullet$ bit.ly/future-olympic-events

Please contact us with any and all questions regarding this encyclopedia; we're happy to "field" your questions. 


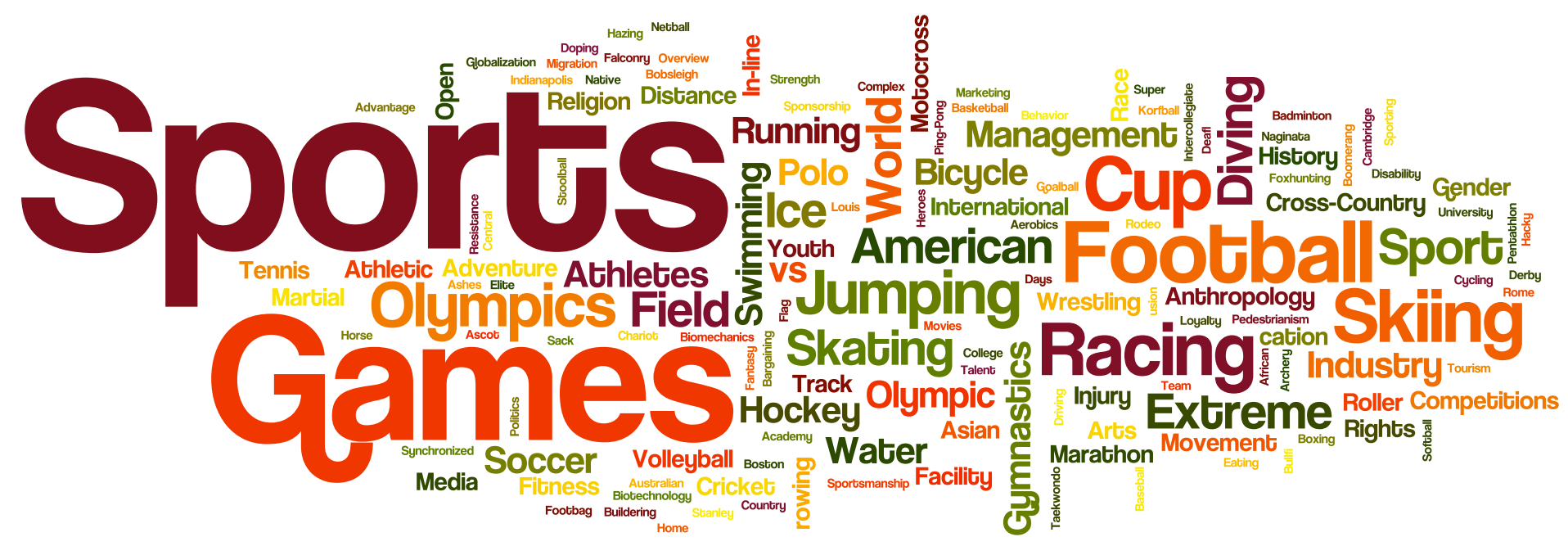

\section{Sports-related fun facts!}

Softball first came about by sewing together a boxing glove; it later became popular as a way for firemen to keep busy between fires.

In a precursor of water polo called water derby, competitors bobbed around on barrels while hitting a ball with a mallet.

Lieutenant (later General) George S. Patton participated in the modern pentathlon at the Stockholm Olympics in 1912; he might have won had he not done so poorly in the shooting event, where he insisted on using his service revolver while the rest of the pentathletes used target pistols.

The theologian Martin Luther bowled, an activity which reminded him of the Christian's duty to knock down the devil; John Calvin also enjoyed bowling, although he saw most other sports as a hindrance to holy living.

It is often claimed that stoolball's name derived from the fact that the first bats were three-legged milking stools, from which modern bats were developed.

The entire first day of the original modern Olympics was devoted to religious rituals—a kind of prolonged opening ceremony when religion mattered more than patriotism or commercial glitz.

Prior to 1937, the national flags of Lichtenstein and Haiti were identical by coincidence; a fact neither country discovered until they competed in the 1936 Summer Olympics in Berlin, Germany.

The American football huddle was invented at Gallaudet University, a school for the deaf, in 1894. The huddle was created to prevent opposing teams from seeing play decisions being "talked" out with sign language. Nowadays the huddle serves a similar purpose; as cameras get better at providing up-close coverage, huddles hide players' mouths so their lips can't potentially be read.

The Doggett's Coat and Badge, a rowing race held on the Thames each year, is considered by many to be the oldest continuously held sporting competition of any kind in the world.

The earliest recorded attempt to move skating from the winter ice was made by Joseph Merlin (1735-1803), a Belgian maker of musical instruments. He introduced roller skating to the public at a reception in London in 1760. As he played the violin and skated about for the crowd, Merlin, his violin, and a large mirror discovered that he could not turn or brake on his new invention.

The original purpose of relay races was to deliver messages across great expanses. The Aborigines of Australia sent runners from tribe to tribe, passing messages and legends. When the distance was too great for one runner to cover, the message would be passed on from runner to runner.

Mark Twain tried surfing in Hawaii in 1860s, as detailed in his book Roughing It.

Jack London (author of Call of the Wild) wrote about his attempts at surfing in an article in the October 1907 issue of Woman's Home Companion.

宝库山 BERKSHIRE PUBLISHING GROUP | www.berkshirepublishing.com | cservice@berkshirepublishing.com | Tel +1 4135280206 